This item was submitted to Loughborough's Research Repository by the author.

Items in Figshare are protected by copyright, with all rights reserved, unless otherwise indicated.

\title{
Dynamic properties of cortical bone tissue: impact tests and numerical study
}

PLEASE CITE THE PUBLISHED VERSION

http://www.ttp.net/1660-9336.html

\section{PUBLISHER}

(c) Trans Tech Publications Inc.

\section{VERSION}

AM (Accepted Manuscript)

\section{LICENCE}

CC BY-NC-ND 4.0

\section{REPOSITORY RECORD}

Abdel-Wahab, Adel A., and Vadim V. Silberschmidt. 2019. "Dynamic Properties of Cortical Bone Tissue: Impact Tests and Numerical Study". figshare. https://hdl.handle.net/2134/8706. 
This item was submitted to Loughborough's Institutional Repository (https://dspace.lboro.ac.uk/) by the author and is made available under the following Creative Commons Licence conditions.

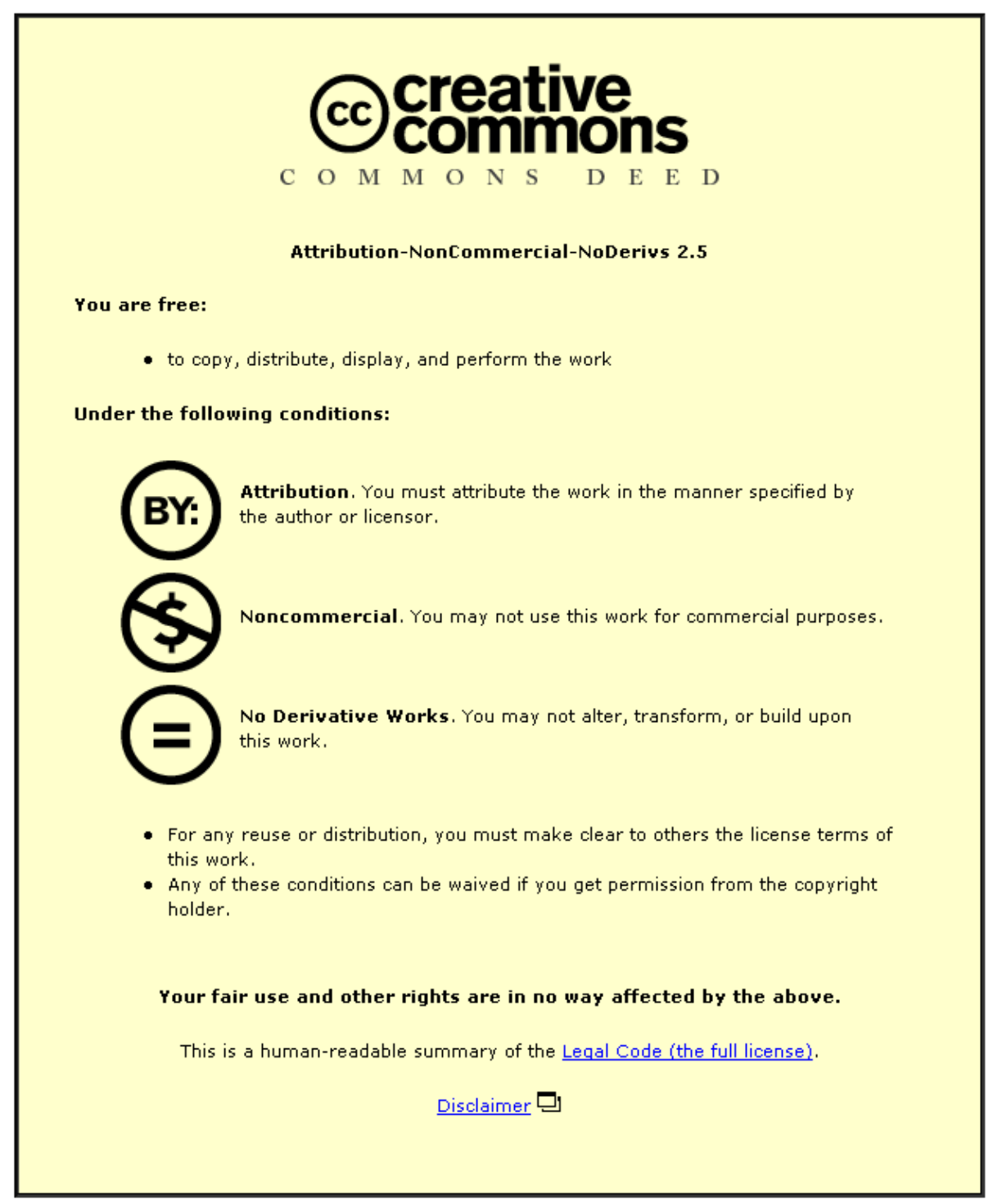

For the full text of this licence, please go to: http://creativecommons.org/licenses/by-nc-nd/2.5/ 


\title{
Dynamic Properties of Cortical Bone Tissue: Impact Tests and Numerical Study
}

\author{
Adel A. Abdel-Wahab ${ }^{\mathrm{a}}$ and Vadim V. Silberschmidt ${ }^{\mathrm{b}}$ \\ Wolfson School of Mechanical and Manufacturing Engineering, Loughborough University, \\ Loughborough, Leicestershire, LE11 3TU, UK \\ ${ }^{a}$ a.a.mohamed@lboro.ac.uk, ${ }^{b}$ V.Silberschmidt@lboro.ac.uk
}

Keywords: cortical bone; dynamic; impact; finite-element; Izod test.

\begin{abstract}
Bone is the principal structural component of a skeleton: it assists the load-bearing framework of a living body. Structural integrity of this component is important; understanding of its mechanical behaviour up to failure is necessary for prevention and diagnostic of trauma. Bone fractures occur in both low-energy trauma, such as falls and sports injury, and high-energy trauma, such as car crash and cycling accidents. By developing adequate numerical models to predict and describe the deformation and fracture behaviour up to fracture of a cortical bone tissue, a detailed study of reasons for, and ways to prevent or treatment methods of, bone fracture could be implemented.
\end{abstract}

This study deals with both experimental analysis and numerical simulations of this tissue and its response to impact dynamic loading. Two areas are covered: Izod tests for quantifying a bone's behaviour under impact loading, and a 3D finite-element model simulating these tests. In the first part, properties of cortical bone tissue were investigated under impact loading condition. In the second part, a 3D numerical model for the Izod test was developed using the Abaqus/Explicit finiteelement software. Bone has time-dependent properties - viscoelastic - that were assigned to the specimen to simulate the short term event, impact. The developed numerical model was capable of capturing the behaviour of the hammer-specimen interaction correctly. A good agreement between the experimental and numerical data was found.

\section{Introduction}

Bone is one of the most challenging natural materials that provide a structural support of the body. Therefore, its structural integrity is significant. Bone fractures have significant health, economic and social consequences. Both healthy and unhealthy bones are susceptible to fracture due to lowor high-energy trauma. High-energy trauma involves, for instance, car or cycling accidents, whereas low-energy trauma, such as falls, contact sports. When loads are applied to whole bones they exhibit structural behaviour. Factors such as the mass of bone, its material properties and geometry as well as the magnitude and orientation of the applied loads affect this behaviour. Bones are fractured when they are exposed to rigorous loads that in turn generate stresses exceed its ultimate strength. Thus, a fracture event occurs initially at the material level that eventually affects the load carrying capacity of the whole bone at its structural level. To investigate the fracture of bone at the material level, a set of parameters that indicates its behaviour is required [1]. It is worth mentioning that bone is viscoelastic material. Therefore, this variant has to be considered when dealing with spontaneous events, such as impact.

Numerous previous studies have been devoted to analysis of quasi-static mechanical properties of a cortical bone tissue, but less attention has been paid to its dynamic mechanical characterization. A few papers were found in the literature dealing with dynamic properties of this tissue. For instance, both dynamic and static material properties of a human femur were investigated using a split Hopkinson bar technique and tests with a universal testing machine [2]. The average dynamic Young's modulus of $19.9 \mathrm{GPa}$ was found to be 23\% greater than that for static loading - $16.2 \mathrm{GPa}$. More recently, the effect of the strain rate on the mechanical properties of human cortical bone was investigated by Hansen et al. [3]. The results of that study showed a strong effect of the strain rate 
on the post-yield deformation than on macroscopic yielding initiation. In addition, the yield and failure stress as well as the failure strain decreased for strain rates higher than $1 \mathrm{~s}^{-1}$. Furthermore, strain at yield was invariant and started to decrease after strain rate higher than $10 \mathrm{~s}^{-1}$. Another study by the same research group and based on the fact that the impact energy absorption capacity of bone declines, and its mineral content increases with age [4]. Therefore, Currey et al. [5] studied the behaviour of human femoral bone under quasi-static and impact loading and their relations to mineral content. Though a good correlation was found between the impact absorption energy and the work of fracture; however the changes in mineral content alone does not explain the degradation in toughness and probably some other features associated with age which degrade the mechanical quality of compact bone.

In terms of bone impact characteristics, only preliminary data are available in the literature. For instance, Panagiotopoulos et al. [6] used a Charpy impact test to measure the energy absorbed by strips cut from proximal femur and its relation to age and gender. In a related experimental work, studying cases of fall, in-vitro bone toughness was determined as an area under the loaddisplacement curve obtained in tensile/compression tests using a very low strain rate [7]. However, the load-displacement characteristics of bone are dependent on the rate of the load. Employing an Izod impact tester, [8] investigated the absorbed energy and the impact strength of a mandible at different positions. Longitudinal human cortical specimens were tested in a tensile impact tester at a strain rate of $133 \mathrm{~s}^{-1}$ [9]. A marked non-linearity was observed in the stress-strain behaviour including plastic deformation and strain-hardening effects. The mean tensile impact strength and impact energy were $126.3 \pm 33.1 \mathrm{MPa}$ and $18790 \pm 7355 \mathrm{~J} / \mathrm{m} 2$, respectively. In a recent study, Lee et al. [10] tested non-mineralized and mineralized materials, such as cortical bone utilizing a dropweight test to investigate the impact strength along with the impact damage. In a similar study, longitudinal human cortical specimens were tested in a tensile impact tester at a strain rate of $133 \mathrm{~s}$ 1 (Saha and Hayes 1976). A marked non-linearity was observed in the stress-strain behaviour, including plastic deformation and strain-hardening effects. The mean tensile impact strength and impact energy were $126.3 \pm 33.1 \mathrm{MPa}$ and $18790 \pm 7355 \mathrm{~J} / \mathrm{m} 2$, respectively. In another study, dynamic tensile material properties of a human pelvic cortical bone were measured at different cortex positions using a high-rate servo-hydraulic Material Testing System [11].

With an increasing number of bone fractures due to factors related to ageing, disease or dynamic events and taking into account the complexity of bone's mechanical behaviour, it becomes more and more important to understand and predict this behaviour using numerical models. Though several finite-element models were developed in the automobile industry $[12,13]$; however bone always considered as a linear-elastic material in those models. From mechanics of materials point of view, some previous numerical models were developed using a homogenization theory to predict macroscopic behaviour of cortical bone tissue [14, 15]. Also, a recent study [16] demonstrated adequacy of a Double-Cantilever Beam (DCB) test for determining fracture toughness under pure mode I loading of cortical bone by implementing a new data reduction scheme based on specimen compliance. Despite this body of research, experimental and numerical studies of the dynamic behaviour of a cortical bone tissue attracted less attention. Therefore, this study comprises two parts covering experimental and numerical aspects of such analysis.

The aim of this study is to develop a numerical model to analyse the behaviour of a cortical bone tissue under impact loading. Such a model can be used as a basis for development of more advanced numerical tools capable to predict the behaviour of other bone tissues under arbitrary loading conditions as well as for diseased and osteoporotic bones. To the best of the authors knowledge, considering the modelling of cortical bone tissue at the material level under impact loading event is no longer exist. 


\section{Methods and Materials}

Specimen Preparation. Izod test's longitudinal specimens - along osteons - were cut from fresh bovine femora bones, (aged 1.5-2 years), see Fig.1a. Sixteen specimens were used to ensure the reproducibility of the experimental results. All the specimens had the same dimensions (according to ISO 180): $50 \mathrm{~mm} \times 8 \mathrm{~mm} \times 4 \mathrm{~mm}$ (length $\times$ width $\times$ thickness), see Fig. 1 b. A $300 \mu \mathrm{m}$-deep notch was created perpendicular to the bone axis and along the Radial axis direction using a razor. Specimens were stored at room temperature in a $0.9 \%$ saline solution until tested.

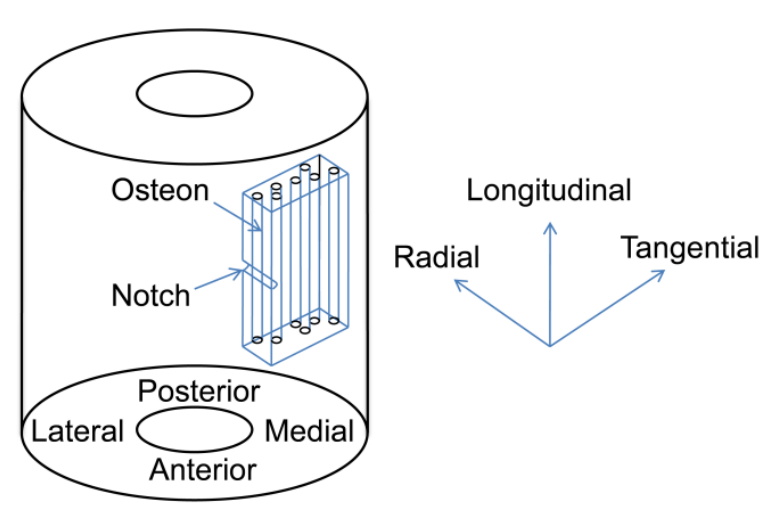

(a)

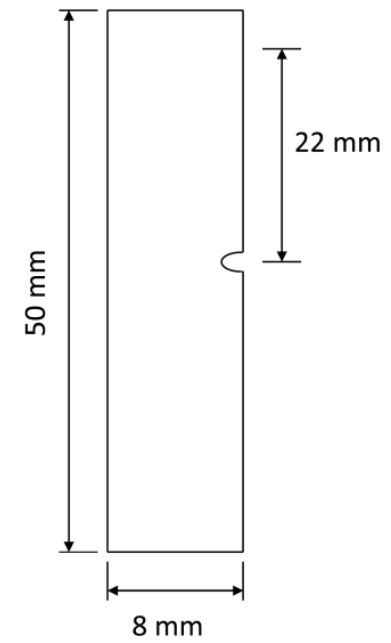

(b)

Fig. 1 (a) Cortical bone axes and direction of specimen cutting; (b) Izod test specimen.

Izod Test. Dynamic impact tests were carried out using a CEAST Resil Impactor. In the tests the bottom half of the specimen was fixed firmly in the machine's vice and a knife-edge wedge was used to define the notch position. The upper half of the specimen was struck by a pendulum hammer with a controlled level of energy. The distance between the notch and the position of hammer strike was standard - $22 \mathrm{~mm}$. In this study a calibrated hammer of $0.334 \mathrm{~kg}$ mass and $0.3268 \mathrm{~m}$ long was used. The nominal hammer energy of $2 \mathrm{~J}$ corresponds to the striking position of $150^{\circ}$ resulting in an impact velocity of $3.46 \mathrm{~m} / \mathrm{s}$. The level of initial energy can be varied by changing the initial angle of the hammer. Two levels of energy were used for each specimen in this study - $0.02 \mathrm{~J}$ (non-destructive) and $0.5 \mathrm{~J}$ (destructive); they correspond to initial angles of $10^{\circ}$ and $58^{\circ}$, respectively. A piezoelectric force transducer was fixed rigidly to the hammer to capture the impact force signal. When the pendulum is released from the pre-defined angle, an impact with the specimen generates a change in the electrical resistance of the piezoelectric sensor that is captured by the data acquisition system - DAS 8000 - connected to the impactor.

\section{Numerical Model}

Geometry and Meshing. The impact tests were simulated with the Abaqus/Explicit finite-element software using a 3-D formulation. The real geometry and masses of the hammer and $300 \mu \mathrm{m}$ notched specimen were used in simulations (see Fig. 2). The surface of the inner cylinder of the upper block of the hammer was coupled to a reference point at the middle of that cylinder, then the reference point was restrained to translate into $\mathrm{x}, \mathrm{y}$, and $\mathrm{z}$ and to rotate around $\mathrm{x}$ or $\mathrm{y}$ axes.

In simulations the initial position of the hammer was close to the specimen, its angular velocity corresponding to the case with an initial angle of $10^{\circ}$ (initial energy of $0.02 \mathrm{~J}$ ). The specimen's support was modelled as rigid; the degrees of freedom of the specimen's bottom part were constrained (see Figs. $2 \mathrm{~b}$ ). Based on a convergence study, the stable time increment was $8.362 \times 10^{-}$ ${ }^{10} \mathrm{~s}$ and 10 nodes modified quadratic tetrahedron (C3D10M). A total number of 8472 elements and 
14203 nodes for the bone specimen and 23695 elements and 6871 nodes for the hammer were used. The force due to contact pressure between the piezoelectric force sensor and counterpart of the specimen was requested in the history output of the finite-element software Abaqus/Explicit.

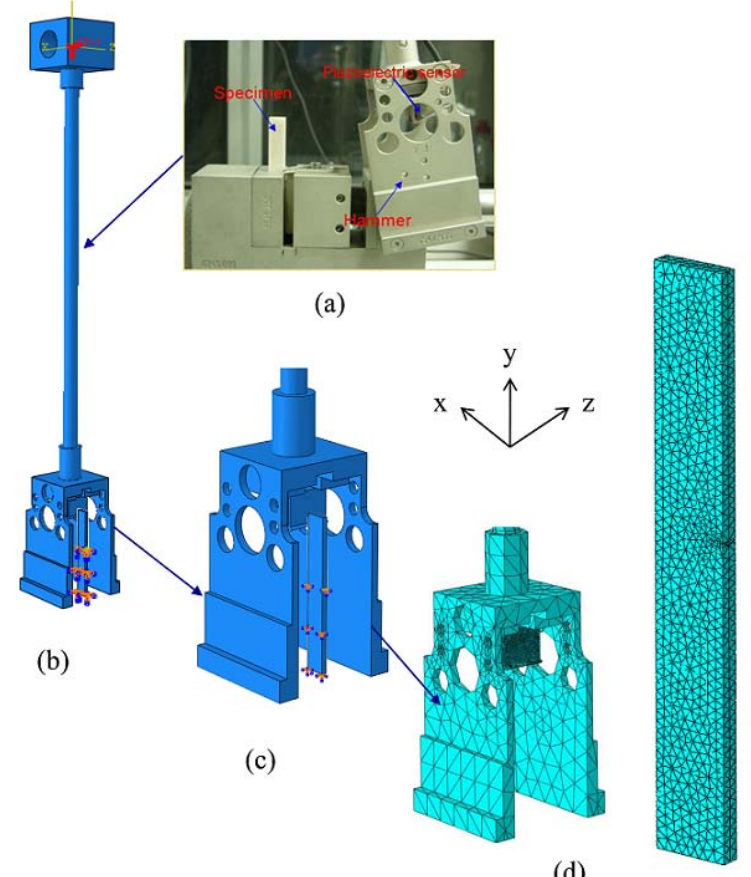

(d)

Fig. 2 (a) Izod test setup; (b) 3-D hammer-specimen assembly; (c) Hammer-specimen interaction; (d) Hammer-specimen interaction mesh.

Material Properties. The elastic material properties for the hammer and the cortical bone tissue used in numerical simulations are given in Table 1 . The viscous behaviour of bones was introduced into the finite-element model in terms of the Prony series expansion based on the normalized creep compliance. These material's constants are shear relaxation modulus ratio, $g=0.13256( \pm 0.01)$ and relaxation time, $\tau=119.57( \pm 0.5)$. All material properties for cortical bone were obtained in our experiments [17]. The values used in this model were the mean values of the anterior cortex position. The following model assumptions were made: (1) homogeneous and isotropic material properties for both the specimen and the hammer; (2) frictionless contact between the hammer and the specimen.

Table 1: Material properties for finite-element model

\begin{tabular}{|c|c|c|c|c|}
\hline Part & Material & Young's modulus (GPa) & Poisson's Ratio & Density (kg/m $\left.\mathbf{m}^{\mathbf{3}}\right)$ \\
\hline Hammer & Steel & 210 & 0.3 & 7850 \\
\hline Anterior longitudinal & Bone & $23.15( \pm 0.72)$ & $0.44( \pm 0.009)$ & $1860( \pm 0.9)$ \\
\hline
\end{tabular}

\section{Results and Discussion}

The aim of this study was to develop and verify a 3D finite-element model of Izod test setup with a mean material data of specimen cut from the longitudinal direction of cortical bone tissue. The intention is to develop this framework that is a step towards a more advanced model to predict the 
deformation and fracture of cortical bone tissue at the material level. In this study, a viscoelastic constitutive material model was used based on our 2D finite-element model of Izod test that was investigating the effect and applicability of different constitutive models, and showed that viscoelastic model is capable to present correctly the behaviour of longitudinal cortical bone under impact loading, when both the linear-elastic and elastic-plastic models underestimated the peak force considerably [18]. In terms of the applied energy, two levels of energy were used - nondestructive and destructive - to analyse the recoverability for the former and the behaviour up to the onset of fracture for the later, and how near are the predictions of the finite-element model. Figure 3 shows the predicted and experimental force-time profile of a low energy impact $-0.02 \mathrm{~J}$. The model gave a good approximation of the experimental force-time behaviour. Still there is an acceptable difference between the two behaviours, but let's recall that the model is based on an isotropic homogeneous constitutive material model, whereas bone is hierarchical and anisotropic and material [19]. It is expected to reduce this difference by introducing both anisotropy and heterogeneity of cortical bone tissue. It is worth noticing that up to a time of $0.5 \mathrm{~ms}$, the numerical results match that of the experimental. This could be explained as up to this point cortical bone behaved elastically and no damage mechanisms has turned up. As damage starts to initiate in biological materials at maximum principal strain of $0.4 \%$ [20, 21], Fig. 4 confirms the absence of such a value up to $0.45 \mathrm{~ms}$. However, a small region ahead of the notch has a value more than $0.4 \%$ at $1.05 \mathrm{~ms}$ and this value reached it maximum immediately before $1.5 \mathrm{~ms}$ - the peak of the force. In this sense, not only the constitutive material definition contributed to the simulation results error, but also the damage mechanism that should be there as well. When the hammer started to retract, the damaged area reduced accordingly to reach to it null value when the hammer-specimen interaction is over $-3 \mathrm{~ms}$.

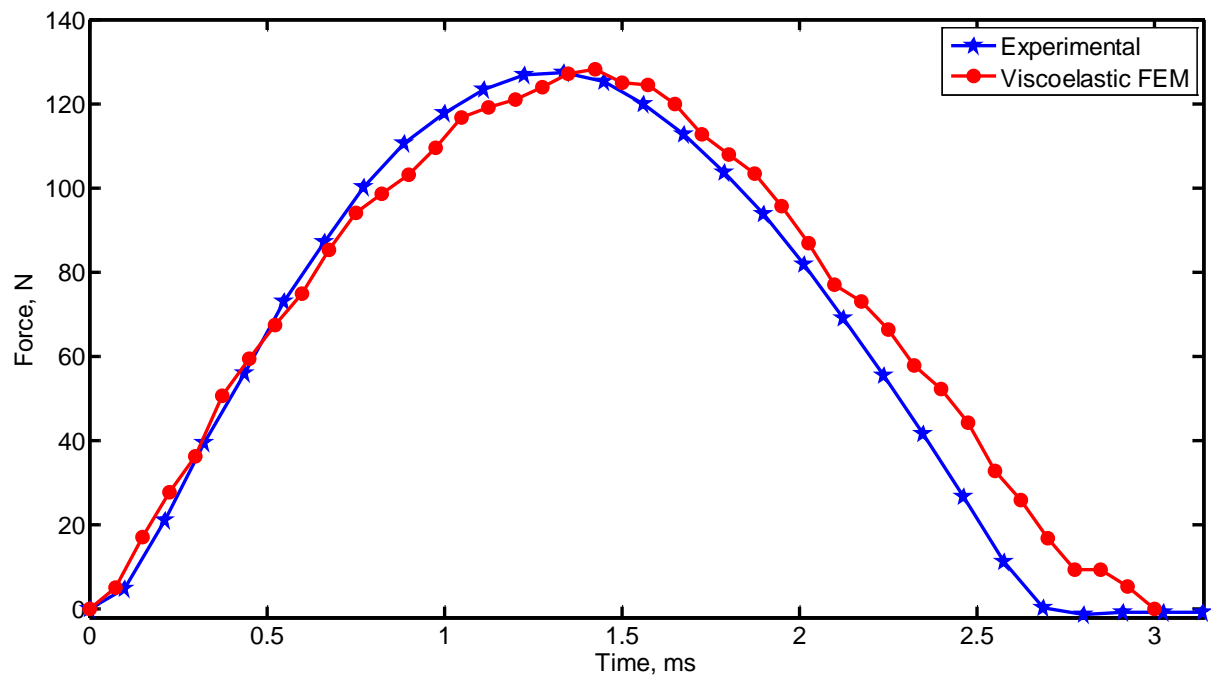

Fig. 3 Comparison of experimental and FEM results for longitudinal cortical bone for energy level of $0.02 \mathrm{~J}$

When a higher energy level was applied both the experimental and the numerical profiles have changed giving higher magnitude of force and lower interaction time. Fig. 5 shows a good agreement between both results up to fracture point. Obviously, the same reasons mentioned earlier for the results difference work here as well. In this case, due to the high energy level, the damage mechanism started earlier than that of lower energy rate due to higher applied forces. Still the introduced model is reliable and was able to capture cortical bone behaviour correctly for both lowand high-energy levels. In the next stage of this research, the model will be improved to simulate exactly the cortical bone behaviour under impact loading. Furthermore, its fracture behaviour using extended finite-element method will be investigated. 


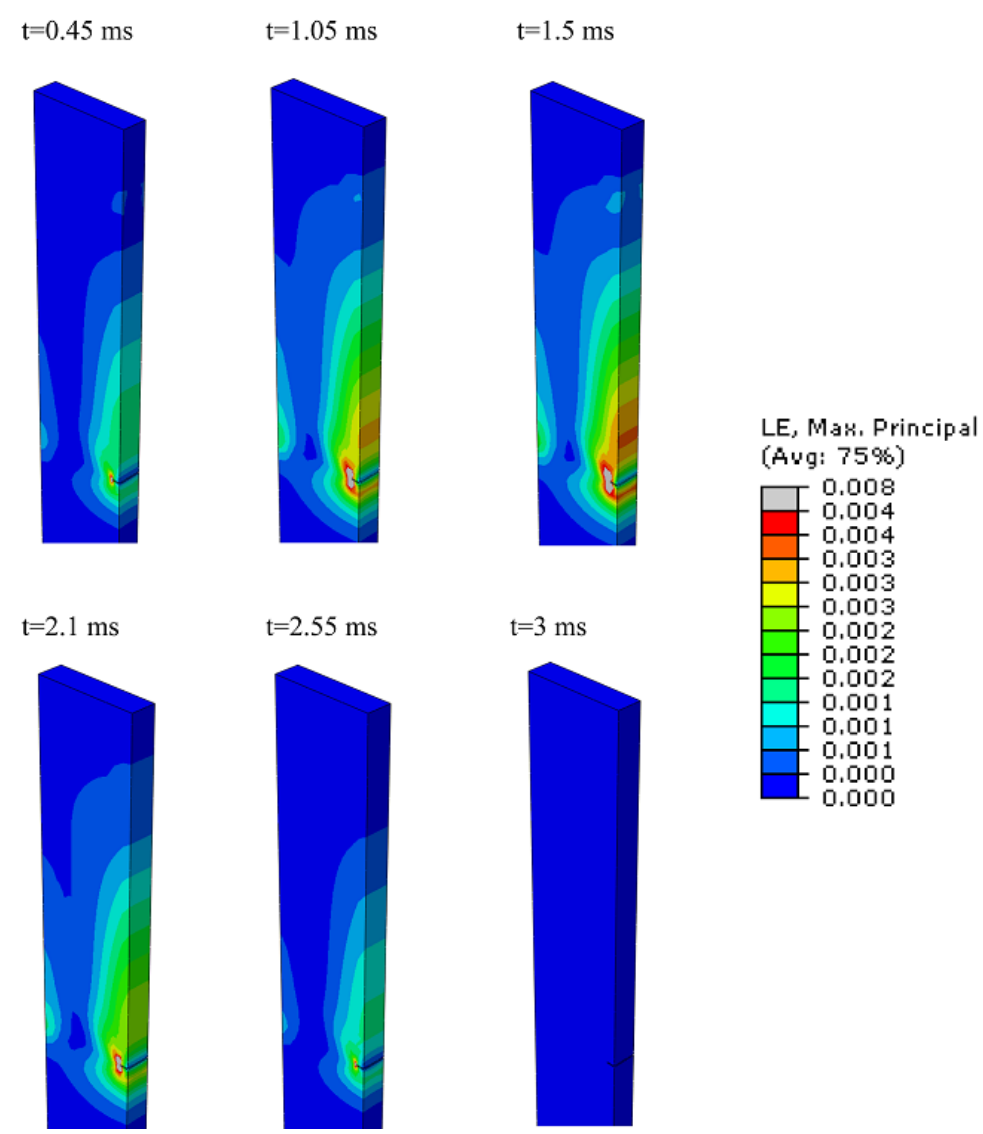

Fig.4 Maximum principal strain distribution at different time increment for longitudinal cortical bone specimen for energy level of $0.02 \mathrm{~J}$

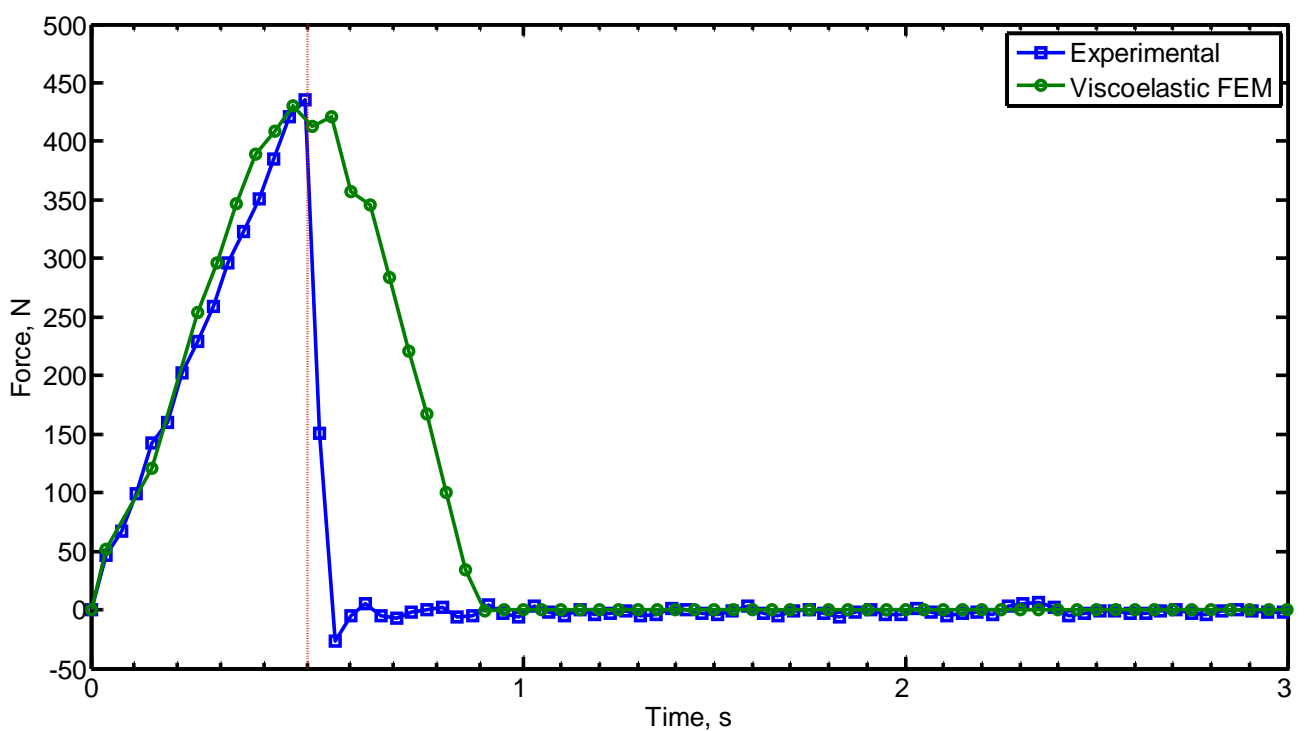

Fig.5 Comparison of experimental and FEM results for longitudinal cortical bone for energy level of $0.5 \mathrm{~J}$

\section{Conclusion}

Experimental tests and finite-element models were developed and implemented to study the transient dynamic behaviour of cortical bone tissue. A model based on the Viscoelastic constitutive material description predicts successfully the behaviour of bovine femoral cortical bone up to the onset of failure under impact loading. Still both the constitutive material model definition includes 
the anisotropy of cortical bone tissue as well as its heterogeneity needs to be implemented to capture more precisely its behaviour under impact loading.

\section{References}

1. Cullinane, D.M., Einhorn, T.A., Biomechanics of bone, in Principles of Bone Biology, Bilezikian, J.P., Raisz, L.G., Rodan, A.R., Editor. 2002, Academic Press San Diego, USA.

2. Fotios, K., Demetrios, D.R., Determination of mechanical properties of human femoral cortical bone by the Hopkinson bar stress technique. J. Biomech., 1990. 23(11): p. 1173-1184.

3. Hansen, U., Zioupos, P., Simpson, R., Currey, J.D., Hynd, D., The effect of strain rate on the mechanical properties of human cortical bone. J. Biomech. Eng. /Transactions of the ASME 130, 011011-1-8, 2008.

4. $\quad$ Currey, J.D., Changes in the impact energy absorption of bone with age. J. Biomech., 1979. 12: p. 459-469.

5. Currey, J.D., Brear, K., Zioupos, P., The effects of ageing and changes in mineral content in degrading the toughness of human femora. J. Biomech., 1996. 29(2): p. 257-260.

6. Panagiotopoulos, E., kostopoulos, V., Tsantzalis, S., Fortis, A.P., Doulalas, A., Impact energy absorbtion by specimens from the upper end of the human femur. Injury, 2005. 36: p. 613-617.

7. Black, J., Hasting, G., Handbook of Biomaterial Properties 1998, London, UK: Chapman Hall.

8. Volkan, K., An assessment of impact strength of the mandible. J. Biomech., 2008. 41: p. 3488- 3491.

9. Saha, S., Hayes, W.C., Tensile impact properties of human compact bone. J. Biomech., 1976. 9(4): p. 243-244.

10. Lee, S., Novitskaya, E.E., Reynante, B., Vasquez, J., Urbaniak, R., Takahashi, T., Woolley, E., Tombolato, L., Chen, Po-Yu, McKittrick, J., Impact testing of structural biological materials. Mater. Sci. Eng. C, 2010. In Press.

11. Kemper, A.R., McNally, C., Duma, S.M., Dynamic tensile material properties of human pelvic cortical bone. Biomed. Sci. Instrum., 2008. 44: p. 417-418.

12. Oshita, F., Omori, K., Nakahira, Y., Miki, K., Development of a finite element model of the human body. In 7th International LS-DYNA Users Conference May 19-21 2002. Dearborn, Michigan.

13. Chawla, A., Mukherjee, S., Mohan, D., Parihar, A., Validation of Lower Extremity Model in THUMS 155. in 2004 International IRCOBI Conference on the Biomechanics of Impact September 22-24, 2004. Indian Institute of Technology, India.

14. Crolet, J.M., Aoubiza, B., Meunier, A., Compact bone: Numerical simulation of mechanical characteristics. J. Biomech., 1993. 26(6): p. 677-687.

15. Aoubiza, B., Crolet, J.M., Meunier, A., On the mechanical characterization of compact bone structure using the homogenization theory. J. Biomech., 1996. 29(12): p. 1539-1547.

16. Morias, J.j.L., de Moura, M.F.S.F., Pereira, F.A.M., Xavier, J., Dourado, N., Dias, M.I.R., Azevedo, J.M.T, The double cantilever beam test applied to mode I fracture characterization of cortical bone tissue. J. Mech. Behav. Biomed. Mater., doi:10.1016/j.jmbbm.2010.04.001, 2010.

17. Abdel-Wahab, A.A., Alam, K., Silberschmidt, V.V., Analysis of anisotropic viscoelastoplastic properties of cortical bone tissues. J. Mech. Behav. Biomed. Mater., doi:10.1016/j.jmbbm.2010.10.001, 2010 (In Press).

18. Abdel-Wahab, A.A., Maligno, A.R., Silberschmidt, V.V. ,Dynamic Properties of Cortical Bone Tissue: Izod Tests and Numerical Study. Compu. Mater. Con., 2010. 19(3): p. 217-238.

19. Rho, J.Y., Kuhn-Spearing, L., Zioupos, P., Mechanical properties and the hierarchical structure of bone. Medical Engineering \& Physics, 1998. 20(2): p. 92-102.

20. Bayraktar, H.H., Morgan, E.F., Niebur, G.L., Morris, G.E., Wong, E.K., Keaveny, T.M., Compression of the elastic and yield properties of human femoral trabecular and cortical bone tissue. J. Biomech., 2004. 37: p. 27-35.

21. Pattin, C.A., Calet, W.E., Carter, D.R., Cyclic mechanical property degradation during fatigue loading of cortical bone J. Biomech., 1996. 29: p. 69-79. 